\title{
Using Medicaid to Buy Private Health Insurance - The Great New Experiment?
}

\section{Citation}

Rosenbaum, Sara, and Benjamin D. Sommers. 2013. “Using Medicaid to Buy Private Health Insurance - The Great New Experiment?” N Engl J Med 369 (1) (July 4): 7-9. doi:10.1056/ nejmp1304170.

\section{Published Version}

doi:10.1056/NEJMp1304170

\section{Permanent link}

http://nrs.harvard.edu/urn-3:HUL.InstRepos:14008385

\section{Terms of Use}

This article was downloaded from Harvard University's DASH repository, and is made available under the terms and conditions applicable to Other Posted Material, as set forth at http:// nrs.harvard.edu/urn-3:HUL.InstRepos:dash.current.terms-of-use\#LAA

\section{Share Your Story}

The Harvard community has made this article openly available.

Please share how this access benefits you. Submit a story.

\section{Accessibility}


patient is the most important patient in the hospital. Clinicians will do what it takes to meet their patients' needs.

That leaves radiologists as the natural choice for managing utilization. Such a shift will require two key changes. The more obvious barrier is the incentive system: there are no rewards for denying an imaging study - one loses a reimbursable exam and expends time in which other reimbursable studies can be read. But the bigger obstacle is the service-provision mindset. Radiologists don't wish to displease referring physicians, lest they take their business to someone who won't question their test-ordering ability.

Referring physicians may believe that radiologists, who generally haven't seen the patient, shouldn't question the appropriateness of clinical suspicion. But preauthorization - standard insurance-company practice for approving advanced imaging - involves decisions by personnel who aren't directly involved in the clinical consultation. Indeed, insurers could save the money that they pay third-party agents to determine the appropriateness of imaging if they trusted radiologists to manage utilization.

Radiologists may resist gatekeeping because of the stigma attached to "rationing" in the United States. Even though the diagnostic pursuit of PE in an intubated patient with severe intracranial injuries may be futile, the radiologist sitting at the outpost of decision making may hesitate to say so and risk being labeled a "death panelist." It will be harder for U.S. radiologists to be gatekeepers than it is for their NHS counterparts, simply because imaging is so abundant here - one can easily justify rationing of something that's truly scarce.

The emphasis on service provision, operations, and efficiency has pushed radiologists to the periphery of clinical decision making. To be effective gatekeepers, they will have to move to the center. They'll have to develop clinical-imaging conferences, act as imaging consultants, and conduct imaging rounds. Radiology leadership must provide incentives for these activities without compromising efficiency, by developing granular metrics for quality. Benchmarks will have to be established for the acceptable proportion of negative studies. Bundled payments for accountable care organizations will offer a sentinel opportunity to face these challenges.

Some radiologists may hope that clinical decision-support systems will do the gatekeeping for them. It's ironic: the profession has great angst about its propensity to be commodified and outsourced, yet it may relinquish its last bastion of clinical involvement to software. But gatekeepers don't simply advise on the best imaging method; they question whether a given diagnosis should be suspected in the first place.

Whoever plays gatekeeper, all clinicians will have to exercise greater restraint in the use of imaging. Radiologists must decide whether to greet the ebb of imaging passively or by stepping forward to captain and manage a rational decline.

Disclosure forms provided by the author are available with the full text of this article at NEJM.org.

From the Department of Radiology, Hospital of the University of Pennsylvania, Philadelphia.

DOI: 10.1056/NEJMp1305679

Copyright (c) 2013 Massachusetts Medical Society.

\section{Using Medicaid to Buy Private Health Insurance - The Great New Experiment?}

Sara Rosenbaum, J.D., and Benjamin D. Sommers, M.D., Ph.D.

The Medicaid expansion is a cornerstone of the Affordable Care Act (ACA), but since the Supreme Court ruled in 2012 that states could opt out of expanding their Medicaid programs, resistance has been strong. With uncertain-to-dim prospects of adoption in roughly half of states, the Obama administration has moved to allow states to adopt a model whereby Medicaid funds could be used to buy private health plans sold through the new health insurance exchanges. ${ }^{1}$ Arkansas has enacted legislation to adopt such an expansion; other states, including Ohio, appear to be negotiating with the federal government over replacing the standard Medicaid approach with premium assistance.

It's clear why the White House is engaged in such a high-stakes effort. Without the Medicaid expansion, the poorest Americans will remain uninsured, since subsidized coverage through the exchanges is available only for U.S. citizens with incomes above $100 \%$ of the federal poverty level (FPL). In many states, including Arkansas, existing Medicaid coverage for adults falls far short of this mark. For example, with the exception of a very limited demon- 


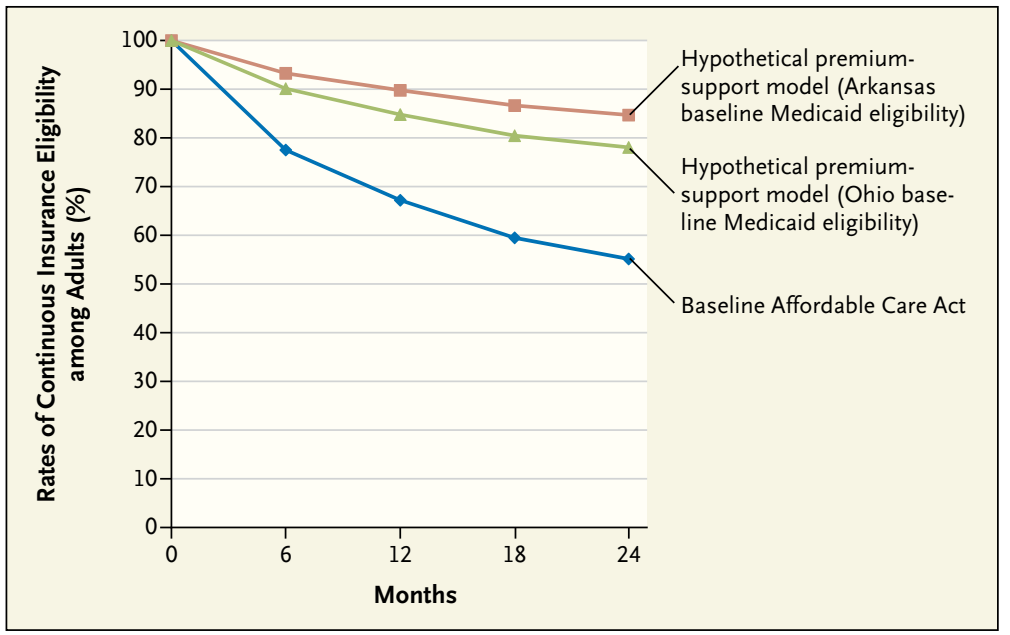

Rates of Continuous Insurance Eligibility among Adults over Time, According to Various Approaches to Expanding Medicaid under the Affordable Care Act.

Rates are based on the authors' analysis of the 2008 Survey of Income and Program Participation. The sample includes all adults 19 to 63 years of age with family incomes of less than $400 \%$ of the federal poverty level (FPL) who don't have employer-sponsored insurance or Medicare (38,737 people). The graph shows the percentage of adults with uninterrupted eligibility for a given type of insurance over time. The three models considered are the baseline Affordable Care Act, in which individuals with family incomes below $138 \%$ of the FPL are in Medicaid and others are in exchange plans; the hypothetical premium-support model using Arkansas baseline Medicaid eligibility, in which individuals meeting the current eligibility criteria for Arkansas Medicaid remain in Medicaid (income below $17 \%$ of the FPL for parents and $75 \%$ and $83 \%$ for single and married disabled adults, respectively) and all others (including all childless adults) are in exchange plans; and the hypothetical premium-support model using Ohio baseline Medicaid eligibility, in which individuals meeting the current eligibility criteria for Ohio Medicaid remain in Medicaid (income below $90 \%$ of the FPL for parents and $65 \%$ and $83 \%$ for single and married disabled adults, respectively) and all others (including all childless adults) are in exchange plans. The differences between the curves are significant at each time point $(\mathrm{P}<0.001)$. See the Supplementary Appendix for more details.

stration program, Arkansas covers no poor adults without minor children, and eligibility for parents is set at $17 \%$ of the FPL (about $\$ 4,000$ in annual income for a family of four). Thus, unless they are pregnant or elderly or have a severe disability, virtually no impoverished working-age Arkansans have Medicaid. The situation is similar in Texas, South Carolina, Louisiana, and other states that either have said no to the expansion or remain on the fence. ${ }^{2}$

Although the idea of using Medicaid to buy private health insurance rather than insuring people directly has been portrayed as radical (the Arkansas "game changer"), it's not a new idea. Since 1965, Medicaid has authorized the secretary of health and human services to use federal funds to pay insurance premiums in states that elect such an approach. But until the ACA created a viable individual insurance market, there was effectively no private insurance for states to buy other than employer-sponsored coverage, which is rarely available to poor workers. Instead, over the past two decades, most states have developed Medicaid managed-care systems that now cover $75 \%$ of beneficiaries. Many of the insurance companies likely to participate in the exchanges already offer Medicaid managed-care plans.

So is this proposal much ado about nothing? Definitely not: moving Medicaid beneficiaries into a new and untested marketplace raises large challenges even as it creates important opportunities. On the plus side, premium support would allow states such as Arkansas that lack a robust Medicaid managed-care market (some states, like Arkansas, currently use only a limited form of managed care known as "primary care case management") to enroll the large 2014 expansion population into larger, more organized plans.

In addition, such arrangements might improve enrollment stability and continuity of care, even in states with robust Medicaid managed-care markets. Our research suggests that low-income adults experience so much income fluctuation that 28 million annually could "churn" across the Medicaid-exchange divide, ${ }^{3}$ set by the ACA at $138 \%$ of the FPL. Without health plans spanning both markets, shifts in financing could disrupt coverage and care. Buying exchange plans with Medicaid funds might shield families from the effect of small income shifts, since they could keep their plans and providers regardless of whether Medicaid or federal premium subsidies were paying the bill at any given moment.

Using national survey data and methods similar to those we've used previously, ${ }^{3}$ we estimate that purchasing coverage in an exchange could reduce churning by nearly two thirds in states such as Arkansas that currently have highly restrictive Medicaid coverage for adults (see graph; for methods, see the Supplementary Appendix, available with the full text of this article at NEJM.org). However, in states such as Ohio, whose income limits under traditional Medicaid are higher, this policy could create churning between the traditional Medicaid- 
eligible group and the expansion group (which will now be buying exchange plans). Although that effect would reduce potential gains in coverage stability, there would still be less churning than there would under a Medicaid expansion that doesn't use premium assistance. In both cases, this analysis assumes that people shifting from Medicaid-funded private coverage (when their income is below 138\% of the FPL) to tax-credit-supported private coverage (when their income increases) would have a fairly seamless transition and could remain with the same plan and provider networks. But as discussed below, such seamlessness is hardly guaranteed.

A third potential advantage of using Medicaid to buy private insurance is the higher providerpayment rates offered by private insurers, which might improve beneficiaries' access to care. This advantage will materialize only if insurers' provider networks agree to care for a new patient population, but networks that don't already treat Medicaid beneficiaries may resist this expanded line of business. Indeed, similar provider resistance was an original contributing factor to the development of separate Medicaid managed-care products with distinct networks.

There are also major challenges involved in using Medicaid to buy private insurance. Medicaid provides more extensive coverage and lower cost sharing than private health insurance, and plans selling services to Medicaid agencies will need to abide by Medicaid's coverage rules, according to guidance on premium assistance issued by the Department of Health and $\mathrm{Hu}-$ man Services (DHHS). The guidance appears to restrict the use of Medicaid for buying private insurance to either an additional coverage option for newly eligible adults or part of time-limited demonstrations testing compulsory premium assistance for newly eligible people while exempting medically frail beneficiaries. The DHHS has yet to address other important questions. Can states require newly eligible parents to enroll in plans separate from those that their children belong to? Will plans be required to assure continuous coverage even during transitions between Medicaid and exchanges as people's incomes fluctuate? Will insurers be required to contract with traditional safety-net providers such as community health centers? Medicaid networks tend to use many such providers, who have greater experience than traditional private medical practices in serving poor adults with complex clinical and social needs.

But cost may remain the largest obstacle to a premium-support model. Many policymakers oppose the Medicaid expansion because they believe it's financially unsustainable. ${ }^{4}$ Buying private insurance for beneficiaries would probably raise costs further, chiefly because private insurers pay providers much more than Medicaid does. The Congressional Budget Office estimates that tax credits for coverage purchased in exchanges will cost $\$ 9,000$ annually per adult, $50 \%$ more than the $\$ 6,000$ in projected costs per Medicaid beneficiary, ${ }^{5}$ although these differences could vary greatly by state. Some analysts argue that private insurers in a competitive marketplace will find ways to save thousands of dollars per beneficiary, but no evidence from either the private insurance or Medicaid managed-care markets supports such claims. The DHHS's recent guidance does not elaborate on existing federal regulations prohibiting states from purchasing private plans unless costs are "comparable" with those of traditional Medicaid. But unless private insurers reduce provider payments to Medicaid rates (or close to them), it's unclear how most states could meet that standard.

Given the politics surrounding the Medicaid expansion, using Medicaid to buy private insurance will continue to generate great interest. Ultimately, the most important aspect of premium assistance may be its appeal to conservative politicians who are skeptical of the ACA generally and the Medicaid expansion in particular - even if the policy differences between an expansion featuring robust Medicaid managed-care and private insurance coverage are less dramatic than they might first appear. If the challenges can be resolved and the approach encourages widespread state participation in expanding Medicaid, the U.S. health care system will be a far better place for our poorest citizens.

Disclosure forms provided by the authors are available with the full text of this article at NEJM.org.

From the Department of Health Policy, George Washington University School of Public Health and Health Services, Washington, DC (S.R.); and the Department of Health Policy and Management, Harvard School of Public Health, Boston (B.D.S.).

1. Pear R. States urged to expand Medicaid with private insurance. New York Times. March 22, 2013:Al4

2. Where each state stands on ACA's Medicaid expansion. Washington, DC: The Advisory Board, 2013.

3. Sommers BD, Rosenbaum S. Issues in health reform: how changes in eligibility may move millions back and forth between Medicaid and insurance exchanges. Health Aff (Millwood) 2011;30:228-36.

4. Sommers BD, Epstein AM. U.S. governors and the Medicaid expansion - no quick resolution in sight. N Engl J Med 2013; 368:496-9.

5. Elmendorf DW. Estimates for the insurance coverage provisions of the Affordable Care Act Updated for the recent Supreme Court decision. Washington DC: Congressional Budget Office, 2012.

DOI: 10.1056/NEJMp1304170

Copyright $(\odot 2013$ Massachusetts Medical Society. 